\title{
Corrosion of reinforcement induced by environment containing chloride and carbon dioxide
}

\author{
VLADIMÍR ŽIVICA \\ Institute of Construction and Architecture of the Slovak Academy of Sciences, Dúbravská cesta 9, 84503 Bratislava 45, \\ Slovak Republic
}

MS received 1 April 2003

\begin{abstract}
Reinforced concrete structures during their exploitation may be exposed to the common action of carbonation and chlorides causing corrosion of steel reinforcement. Therefore, the related data seem to be interesting and important when the evaluation of the service life of the structures is the object of interest. This fact was a motivation for the present experimental study on the sequence of action of chloride solutions and carbonation of the embedding concrete. The results obtained show that carbonation of concrete foregoing the action of chloride solutions may intensify the process of corrosion of steel reinforcement in comparison to the converse sequence of the action of mentioned media. At the same time the natrium chloride solution has been shown as a more aggressive medium opposite to the calcium and magnesium chloride solutions.
\end{abstract}

Keywords. Steel reinforcement; corrosion; carbonation; chlorides.

\section{Introduction}

The main and frequent cause of corrosion of reinforcement in reinforced concrete structures is chloride attack and carbonation.

Chlorides come from several sources. They can be cast in concrete but often they can diffuse into concrete as a result of sea salt spray and direct seawater wetting. Further, they can diffuse into concrete due to the application of chloride de-icing salts and at the storage of chloride substances in concrete tanks and like wise.

The source of carbonation of concrete is atmosphere preferably in the areas of industrial and transport activities.

Mechanisms involved in the carbonation, chloride attack and corrosion of reinforcement have been studied by many researchers (Bernander and Öberg 1966; Nürnberger 1984; Jones et al 1996).

As is well known, the corrosive effect of carbonation is based on the decreasing trend of alkalinity of pore liquid in concrete and the resulting depassivation of steel, making it able to corrode. The significant influence of various factors like cement type, $w / c$ ratio, mineral additives as well as the conditions of concrete preparation and site have been reported in many studies. Also the significant influence of ambient temperature and relative humidity, and permeability of concrete has been shown. The relative humidity has been shown as a deciding factor of carbonation rate, which is at a maximum within range between 50 and $70 \%$ of relative humidity.

Corrosive effect of chlorides is based on their ability to destroy the electrochemical condition of the passive state of reinforcement even under the existing alkalinity in the concrete.
Chlorides are reported to cause corrosion of reinforcement in three ways: (i) chlorides are held to pass through the protective oxide film, which exists on the steel surface in a high $\mathrm{pH}$ environment, hence, depassivating the steel. A possible colloidal dispersion of the surface by chlorides, (ii) adsorption of chlorides on the steel surface and thus promoting the hydration of metal ions and facilitating depassivation and (iii) it is supposed that chlorides are able to compete with hydroxyl ions for the ferrous ions produced by corrosion process. Formated complex of ferric chloride diffuse away from the steel surface developing the passive layer breakdown.

Due to the often common occurrence of carbonation and chloride effects on the reinforced concrete structures in practice, the related principles and information of the resulting corrosion process of reinforcement are interesting. Unfortunately, the data are very limited. It is reported that a reduction in $\mathrm{pH}$ in concrete due to its carbonation will increase the severity of the attack in the presence of chlorides (Broomfield 1992). According to Roper and Baweja (1991) the interactive effects of carbonation and chloride lead to much more rapid corrosion of reinforcement than where both the phenomena act separately. The effect was more pronounced when the $w / c$ ratio was increased.

The results of the study on the common action of carbonation and chlorides on reinforcement are presented here.

\section{Experimental}

Mortar test specimens (prisms $40 \times 40 \times 120 \mathrm{~mm}$ ) with embedded steel specimens, also called corrosion sensors, 
for electrical resistance were used for the study. The material of the embedding mortar represented the mixture of Portland cement (STN 72 2121) and silica sand (STN 72 1208) with ratio $1: 5$ and $w / c 0.78$.

Regime of curing of the test specimens are given here: (i) $24 \mathrm{~h}$ after the preparation in the moulds under the ambient temperature, $23^{\circ} \mathrm{C}$ and relative humidity $(\mathrm{RH})$, ca $95 \%$, (ii) after demoulding for 7 days at $19-23^{\circ} \mathrm{C}$ and $\mathrm{RH}, 45-55 \%$, and (iii) equal parts of the test specimens were cured in three ways: (a) carbonation under the concentration of $15 \% \mathrm{CO}_{2}$, ambient temperature, $30^{\circ} \mathrm{C}$ and $\mathrm{RH}, 60 \%$, (b) penetration by the saturated solution of natrium, calcium, and magnesium chlorides and (c) penetration by the same solutions followed by carbonation.

The penetrated test specimens were exposed to curing cycles consisting of these conditions: $7 \mathrm{~h}$ exposition to temperature, $50^{\circ} \mathrm{C}$, cooling for $1 \mathrm{~h}$ under laboratory conditions and submersion in the saturated solutions of the mentioned chlorides at laboratory temperature.

The progress of carbonation of the test specimens was ascertained by colour test using $1 \%$ phenolphthalein ethyl alcohol solution. The penetration of chloride solutions was controlled by $\operatorname{Ag}(\mathrm{NO})_{3}$ test. Progress of both media continued till total carbonation and chloride penetration into test specimens.

For controlling the embedded corrosion sensors, electrode potential vs saturated calomel electrode (SCE) and electrical resistance methods were used (Zivica 1995, 2000).

The chlorides used were chemically pure substances. The concentrations of saturated solutions are: $\mathrm{NaCl}$, $16 \mathrm{wt} \% ; \mathrm{CaCl}_{2}, 27 \cdot 3 \mathrm{wt} \%$ and $\mathrm{MgCl}_{2}, 26 \cdot 3 \mathrm{wt} \%$.

\section{Results and discussion}

Figure 1 shows that the penetration of chloride solutions into mortar test specimens caused decrease of the starting positive values of electrode potential (EP). At the end of penetration these occurred around the value of $-450 \mathrm{mV}$ vs SCE. It means that the starting electrochemically passive status of the embedded corrosion sensors due to penetration was changed into active one representing a possibility of their corrosion. As it may be seen in figure 1, during subsequent carbonation, EP values occurred in the negative active area predominantly under the electrochemically active value of $-350 \mathrm{mV}$ vs SCE. Electrochemically passive EP with the value of $-180 \mathrm{mV}$ vs SCE at the mortar test specimens penetrated by $\mathrm{MgCl}_{2}$ solution was reached at the end of carbonation.

An entire situation may be observed in figure 2 showing the changes of EP values of corrosion sensors embedded in the mortar test specimens which were carbonated beforehand and then penetrated by chloride solutions. It may be seen that during carbonation EP values occurred in the electrochemically passive area showing positive values. But the following penetration caused their sudden decrease and negative values reaching around $-500 \mathrm{mV}$. Later during carbonation a moderate decrease of the negative EP values occurred. At the end of penetration the status of corrosion sensors embedded in the mortar test specimens penetrated by $\mathrm{CaCl}_{2}$ and $\mathrm{MgCl}_{2}$ solutions with the $\mathrm{EP}$ values -250 and - $350 \mathrm{mV}$ was electrochemically passive but those penetrated by $\mathrm{NaCl}$ solution with $\mathrm{EP}$ value $-400 \mathrm{mV}$ electrochemically active.

Corrosion as a consequence of the found electrochemically active status of the embedded corrosion sensors evocated by the combination of carbonation and penetration, is documented in figures 3 and 4 . These show as an effect of corrosion the loss of the material of the embedded corrosion sensors.

A comparison of figures 3 and 4 shows a significant difference between the illustrated curves of the rate of corrosion. At the combination of carbonation-penetration, these are of clear exponential character (figure 4). But at

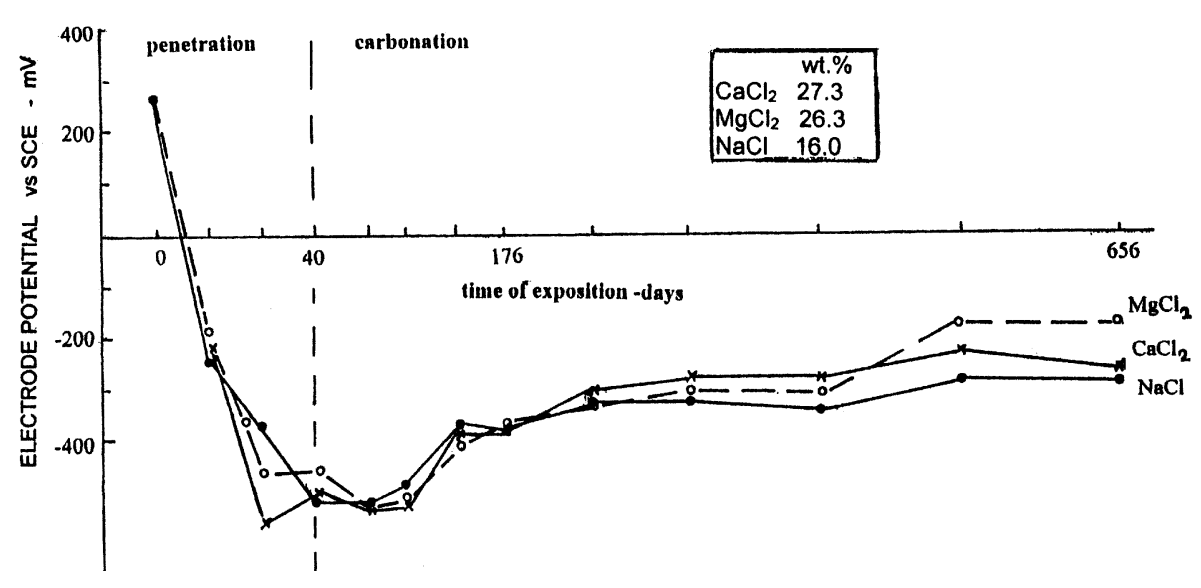

Figure 1. Electrode potential of corrosion sensors embedded in the mortar test specimens penetrated by chloride solutions and subsequently exposed to carbonation. 
the combination of penetration-carbonation, entirely different (having approximately reverse $S$ ) characters are seen (figure 3 ). The different characters of the curves indicate the different mechanisms of steel corrosion as a consequence of the sequence of combinations of carbonation and chloride penetration.

A further comparison shows that the maximal value of material loss was reached at the combination of carbonation-penetration by $\mathrm{NaCl}$ solution. Less effect and practically identical values of material loss was reached at the penetration carbonation combination, at this the maximal value of material loss was reached at the penetration of $\mathrm{MgCl}_{2}$, less at penetration of $\mathrm{CaCl}_{2}$ solution.

A practical illustration of the effects of the sequence of combination of penetration-carbonation on the severity

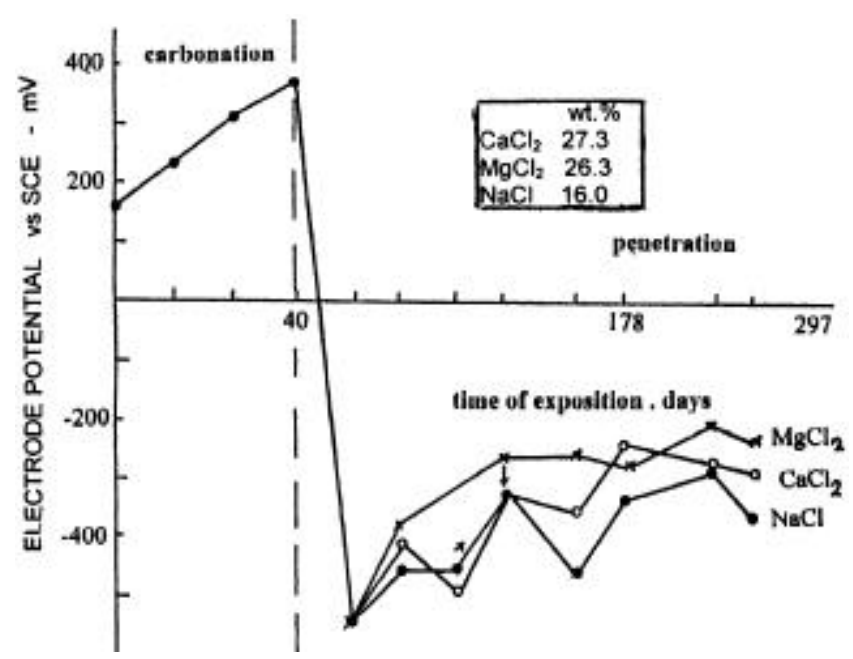

Figure 2. Electrode potential of corrosion sensors embedded in the mortar test specimens exposed to carbonation and subsequently penetrated by chloride solutions. of corrosion in dependence on the type of penetrated chloride solution is shown in figure 5.

It may be seen that the severity of corrosion significantly increased under the combination of carbonationpenetration opposite to that under the converse combination. This effect was the most pronounced when natrium chloride solution was penetrated, and less in the case of calcium chloride solution. An increase of the severity of corrosion of the carbonated mortar test specimens by their subsequent penetration represents $114 \%$ by $\mathrm{NaCl}$ and $80 \%$ by $\mathrm{CaCl}_{2}$ - in comparison with mortar test specimens penetrated by the identical chloride solutions and subsequently carbonated. The severity of corrosion at the penetration of magnesium chloride solution was on the sequence of combinations of penetration-carbonation practically independent. But its level was practically the same at the carbonated test specimens subsequently penetrated by calcium chloride solution. It means that the severity of corrosion was relatively high when the penetrated magnesium chloride was presented independently on the foregoing or subsequent carbonation.

\section{Conclusions}

The results obtained show that the common action of chlorides and carbonation may influence the caused corrosion of reinforcement as given below:

(I) Carbonation of concrete foregoing the following chloride solution penetration into embedding concrete has been found as a factor significantly accelerating the corrosion rate and its intensity in comparison with the converse sequence of the action of both media.

Intensifying effect of the primary carbonation followed by chloride attack is evidently a consequence of the decreased alkalinity of pore solution in concrete and

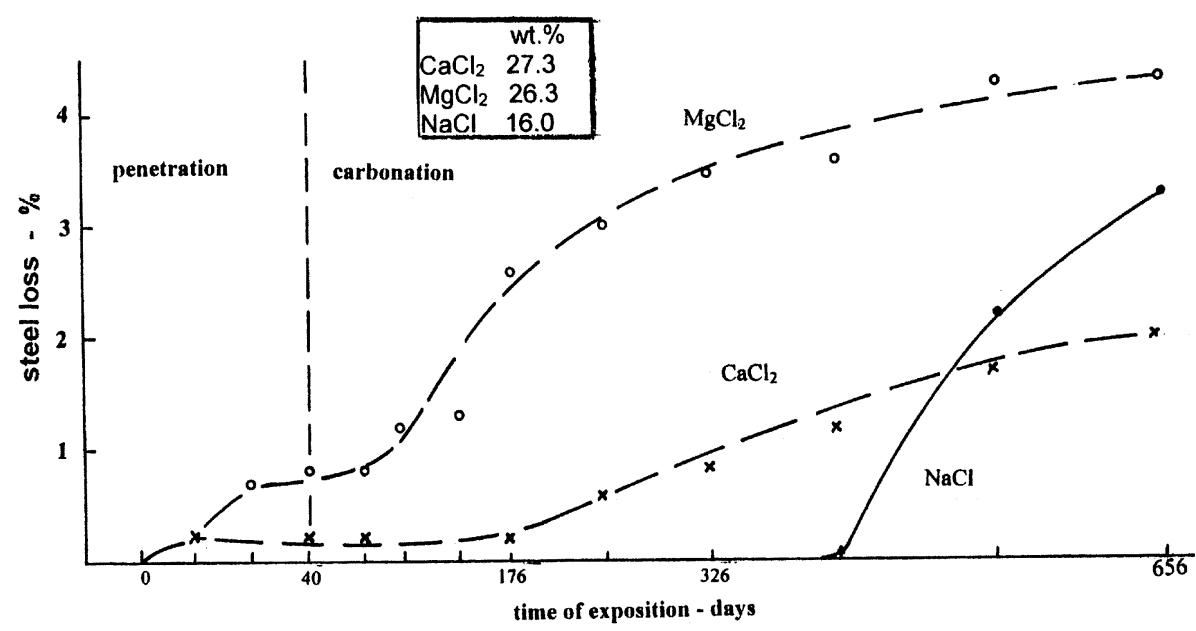

Figure 3. Material loss due to corrosion of corrosion sensors in the mortar test specimens penetrated by chloride solutions and subsequently exposed to carbonation. 


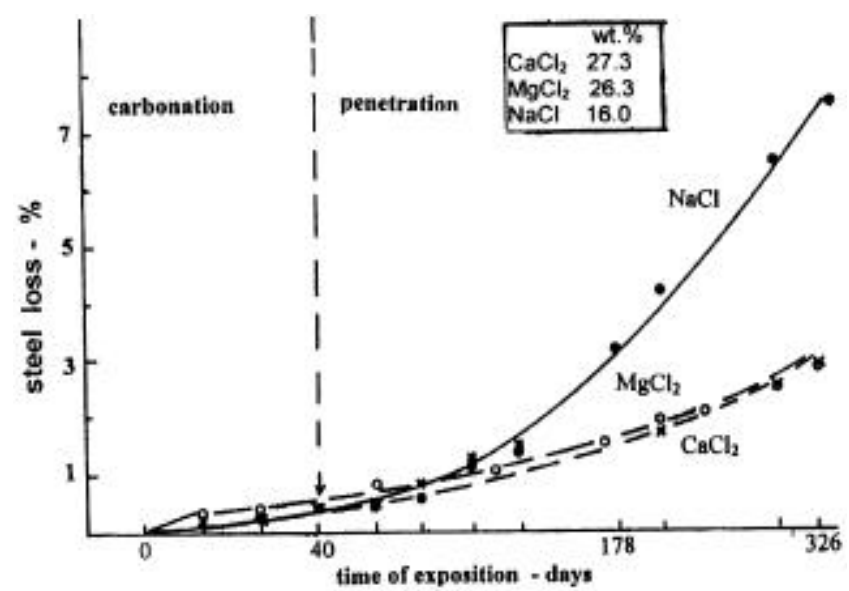

Figure 4. Material loss due to corrosion of corrosion sensors embedded in the mortar test specimens exposed to carbonation and subsequently penetrated by chloride solutions.

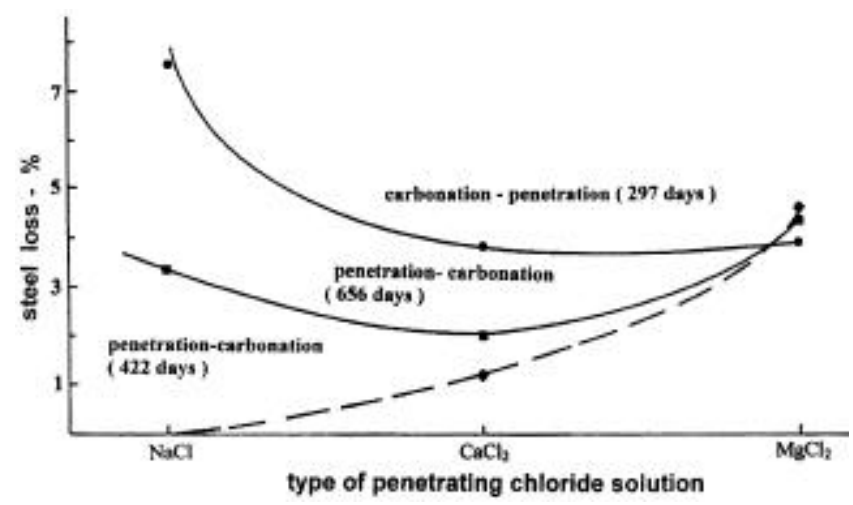

Figure 5. Material loss due to corrosion of sensors in dependence on the subsequence of chloride solution penetration and carbonation, and the time of exposure.

resulted in electrochemically active status of reinforcement becoming more vulnerable to the chloride attack.
(II) Penetrated solution of calcium and magnesium chlorides show practically the same and less aggressivity in comparison with natrium chloride solution. This solution shows the highest aggressivity regardless of its approximately half-concentration of chloride opposite to that of $\mathrm{CaCl}_{2}$ and $\mathrm{MgCl}_{2}$ solutions. A different aggressivity of chlorides under the cooperation of carbonation is worthy of more detailed study.

(III) From practical view point the following results are important: (i) from the view point of the limitation of the danger of corrosion of reinforcement seems to be more suitable for use of chlorides of calcium and magnesium as de-icing salts opposite to natrium chloride, and (ii) the fact that the intensification of chloride corrosion of reinforcement by the foregoing carbonation of concrete is unfavourable but practically ever existing circumstance under the application of de-icing salts. A cause is the fact that reinforced concrete structures are permanently exposed to carbonation forming the conditions for the intensification of corrosion when in winter season the de-icing salts are applied.

\section{References}

Bernander K and Öberg M 1966 Betonwerk + Fertigteiltechnik H11 65

Broomfield J P 1992 Corrosion of steel in concrete (London: E FN Spon) p. 28

Jones M R, Thomas M D A, Dhirx R K and Ng S L D 1996 Durability of building materials and components (London: E FN Spon) p. 107

Nürnberger U 1984 Betonwerk + Fertigteiltechnik H9 601

Roper H and Baweja D 1991 Durability of concrete second international conference (ed.) V M Malhotra (Detroit, Michigan: American Concrete Institute) p. 295

Živica V 1995 Mater. Struct. 18115

Živica V 2000 Constr. \& Build. Mater. 14351 